\title{
7 The formation of economic networks: a proximity approach
}

\section{Ron Boschma, Pierre-Alexandre Balland and Mathijs de Vaan}

\section{INTRODUCTION}

Over the last two decades, scholars from different scientific fields have increasingly acknowledged that network structures play a crucial role in economic activities (Granovetter, 1985; Powell et al., 2005; Cowan et al., 2007; Jackson, 2008). Network structures refer to the particular way relations are organized, which is crucial for the exchange of resources that do not circulate easily through the market, like strategic information, tacit knowledge and trust. Therefore, considerable attention has been given to the analysis of structural properties of networks that favour entrepreneurship, innovation processes, technological change or employment dynamics. A major research concern is to understand how these structures are formed. Since networks are a crucial determinant of economic performance, it is important to understand where this set of relations comes from. This means there is a need to investigate the underlying mechanisms of network formation, i.e. the driving forces behind network structures. Two different, although complementary, perspectives can be adopted to explain relational dynamics. The first driver operates at a 'structural' level and refers to the endogenous mechanisms of network formation (Glückler, 2007; Rivera et al., 2010). Network theory explains how the organization of relationships influences the creation of further relations. The second driver focuses on the 'individual' level and analyses the unequal embeddedness of actors in networks. In this view, it is argued that the tendency to create relations is related to individual characteristics of actors (Cassiman and Veugelers, 2002). Organizational science devotes a lot of attention to the fact that some actors are more capable to support costs of linkages or to benefit from external resources (Cohen and Levinthal, 1990).

In this chapter, we stress the importance of an additional level of analysis introduced in economic geography to explain network formation: the 
'proximity' level. Therefore, we aim at contributing to the emergent literature that explicitly analyses the relationship between proximity and economic networks (Boschma and Frenken, 2010; Balland, 2012; Broekel and Boschma, 2012; Broekel and Hartog, 2013; Ter Wal, 2013). To do so, we build on seminal research initiated by the French school of proximity (Bellet et al., 1993; Rallet and Torre, 1999, 2001; Pecqueur and Zimmermann, 2004; Bouba-Olga and Grossetti, 2008; Carrincazeaux et al., 2008) and more in particular on the analytical distinction proposed by Boschma (2005). The proximity school developed the idea that proximity between actors' attributes is crucial for the coordination of economic activities. Knowledge transfer, communication of strategic information and resolution of conflicts are facilitated by the proximity of actors in different dimensions. We aim at analysing empirically how cognitive, geographical, organizational, institutional and social proximity influence the formation of network structures.

Our empirical analysis focuses on network formation in the global video game industry from 2005 to 2007 . The essential unit of analysis is the relation between actors represented by the co-production of a video game. The analyses are conducted for the total population of firms that developed or published one or more video games for a video game console. Therefore, we investigate the question of whether publishers or developers that have common knowledge bases (cognitive), that are located in the same spatial area (geographical), that belong to the same corporate group (organizational), that have previous relationships (social), and that are embedded in the same institutional context (institutional) are more likely to produce a video game together. Our study focuses on a creative industry, whereas most studies analyse network formation in high-tech industries. Typical to such a creative industry is its project-based production in which new video games are jointly developed (Caves, 2003).

The chapter is organized as follows. The next section discusses how different proximity dimensions influence the formation of economic networks. Then, we describe the data collection, the network database and the specification of the stochastic actor-oriented model. The operationalization of the different forms of proximity is detailed in the following section. Then, we present the main empirical results of the model. The final section concludes and discusses implications for further research.

\section{PROXIMITY DIMENSIONS AND THE FORMATION OF NETWORK STRUCTURES}

By devoting attention to the analytical distinction between different forms of proximity, scholars of the proximity school have contributed to furnish 
a rich framework that complement structural and individual analysis of network formation. The underlying rationale of the proximity framework lies in considering space as central in economic theory, but not as a starting point of the analysis (Gilly and Torre, 2000). This line of reasoning induces that geographical proximity is only understood as one proximity dimension among others. Various definitions and typologies of proximity have been discussed in order to provide a better understanding of the coordination processes of economics activities in the proximity school. ${ }^{1}$ We follow the analytical distinction in five dimensions of proximity proposed by Boschma (2005), and we argue that cognitive, organizational, institutional, social and geographical proximity reduce collaboration costs or risks, and thus facilitate the formation of inter-organizational networks (Boschma and Frenken, 2010; Balland, 2012).

\section{Cognitive Proximity}

Cognitive proximity refers to the degree of similarity of the knowledge bases of organizations (Nooteboom, 2000), and it is a crucial issue to communicate and transfer knowledge. The effective transfer of knowledge and collaboration requires the capacity to identify, interpret and exploit the new knowledge (Cohen and Levinthal, 1990; Nooteboom, 2000). For this reason, the capacity of actors or firms to absorb new knowledge requires cognitive proximity. Thus, external knowledge is more easily evaluated, but also more easily combined and integrated into the internal knowledge. As noted by Frenken (2010), cognitive proximity is certainly the most important dimension observed by organizations when they select their future partners. That is, their own cognitive base should be close enough to the new knowledge in order to communicate, understand and process it successfully. With the notion of cognitive proximity, it is meant that people or firms sharing the same knowledge base and expertise are expected to learn more from each other than if cognitive distance is large. Nooteboom et al. (2007), among others, have demonstrated that cognitive proximity is indeed an important determinant in $\mathrm{R} \& \mathrm{D}$ alliances. It is also visible in patent citations, which have been considered as proxies for knowledge spillovers. Cognitive proximity can be measured by using the similarity of technological classes for patents, the similarity of products or the similarity of educational background of employees between two organizations.

\section{Geographical Proximity}

There is a strong claim that geographical proximity is a prime mover of network formation despite globalization, implying that a great deal of 
interaction still takes place between agents that are geographically proximate (see e.g. Weterings, 2005; Boschma and Ter Wal, 2007; Suire and Vicente, 2009; Hoekman et al., 2010). Boschma (2005) defines geographical proximity in a restricted manner as the physical distance between actors in absolute (e.g. miles) or relative terms (e.g. travel time). This restricted view is possible since other socio-economic dimensions are part of the four other dimensions. Geographical proximity is beneficial for creative activities as effective learning requires face-to-face interaction. Such interaction is easier (and cheaper) to organize when agents are co-located. The relationship between geographical proximity and co-location is not that straightforward though, because they do not necessarily mean the same thing. The need for geographical proximity (or better, face-to-face interactions) may be realized by temporary co-location (bringing agents together by means of fairs, conferences, business meetings, etc.), instead of permanent co-location (Torre and Rallet, 2005; Torre, 2008). In sum, for analytical purposes, it is essential to define geographical proximity in such a restricted manner, and to isolate it from the other dimensions of proximity.

\section{Social Proximity}

The notion of social proximity has its roots in the embeddedness literature (Granovetter, 1985; Uzzi, 1996). This literature indicates that economic relations, creative networks in our case, are embedded in a social context and that, in turn, social relations affect economic outcomes. Boschma (2005) defined social proximity in terms of socially embedded relations between agents at the micro-level. To distinguish analytically creative networks and social proximity, we define social proximity between two organizations as the degree of overlap between the personal networks of the individuals that compose these two organizations. Thus, social proximity refers intrinsically to the personal level. The basic idea of social proximity is that creative networks, i.e. the set of relations between actors created in order to access or combine knowledge, are socially embedded. Such relationships carry strategic information about potential partners, tacit knowledge and trust and thereby increase the probability of organizations to engage in creative networks. What is more, the perceived risk of conflict is also lower as social proximity adds to trust among organizations. Social proximity also plays a role in informal knowledge exchange between employees affiliated to different organizations. Breschi and Lissoni (2009) found that social connectedness between inventors played a significant role in knowledge spillovers. That is, social networks based on personal acquaintances due to common working experiences are impor- 
tant carriers of knowledge exchange based on reciprocity. Agrawal et al. (2006) point out that firms often connect because their employees used to work for the same organization in the past.

\section{Organizational Proximity}

As noted by Balland, Boschma and Frenken (2011), organizational proximity is often associated with networks in the proximity school. Since we aim to explain the formation of network structures in this chapter, it is important to make a clear analytical distinction between organizational proximity and collaboration networks. We make use of the distinction between groups and networks made by Simmel (Grabher, 2006). As such, organizational proximity is not defined by direct or indirect relations but by means of the membership to the same group. In network theory, it is closely related to the concept of two-mode networks (Robins and Alexander, 2004). For instance, research centres owned by the same university, firms belonging to the same parent company, or individuals working for the same organization are organizationally proximate in our view. In this approach, two organizations can share a high level of organizational proximity without having any collaborative interaction. Following Boschma (2005), this dimension involves the rate of autonomy and control that can be exerted in organizational arrangements. As for cognitive proximity, organizational proximity is believed to be beneficial for the formation of relationships in creative networks, because it reduces uncertainty and opportunism. Strong control mechanisms are required to ensure ownership rights and to reap sufficient benefits for own investments in new technology. Markets are poorly equipped to fulfil these tasks, because they tend to generate excessive transaction costs. In addition, formal contracting is almost impossible when it concerns complex and long-term research collaborations in which it is hard to codify what activities will be undertaken, and what kinds of returns will be generated (Nooteboom, 2000).

\section{Institutional Proximity}

Whereas collaboration networks refer to the interactive game played by organizations, institutional proximity refers to the rules of this game. Institutional proximity is associated with institutions at the macro-level (Boschma, 2005) and therefore can be defined by the similarity of informal constraints and formal rules shared by actors (North, 1990). Common representations, routines and incentives structures have a strong impact on the efficiency of knowledge transfer. Both formal institutions (as laws) 
and informal institutions (like cultural norms and values) influence the extent and the way organizations co-ordinate their actions (Kirat and Lung, 1999; Hall and Soskice, 2001). It is a complex notion that comes close to the notion of habitus in sociology, which is a way of conduct, constructed involuntarily through the socialization process of individuals and organizations. Institutional proximity can also be considered as belonging to the same institutional form, as proposed by Ponds et al. (2007). For instance, these authors argue that firms, university and government are different institutional forms with different incentive structures. As such, institutions are enabling mechanisms that provide stable conditions for interactive learning. A classic study on institutional proximity is the empirical study on the adoption of German machinery in Canadian firms (Gertler, 1995), showing that interfirm relationships are often hampered by a lack of institutional proximity between countries (Hall and Soskice, 2001). Then, one can consider that belonging to the same country provides a common institutional framework in which organizations share the same legal framework, language or culture.

\section{DATA AND METHODS}

Researchers aiming to explain the formation of economic network structures face two main challenges. First, they have to collect a complete set of relations among a set of economic actors. This kind of data is often difficult to obtain (Baum et al., 2003; Ter Wal and Boschma, 2009). Second, network data is a specific kind of data, requiring specific econometric models to deal with the non-independence of observations (Snijders et al., 2010). In this section, we discuss our relational database, based on the video game industry from 2005 to 2007 and the statistical model we used: a class of stochastic actor-oriented model.

\section{The Video Games Industry}

In this chapter, we analyse the formation of inter-organizational networks in the video game industry. This creative industry is an interesting case to test whether proximity influences the formation of economic networks, since scholars have stressed the symbiotic relationship between place, culture and economy (Pratt, 2000; Scott, 1997, 2004; Johns, 2005). As most of the empirical studies of networks focus on high-tech, engineering or scientific-based networks, we know relatively little about relational dynamics in creative industries.

Production in creative industries is highly dependent on the interaction 
between multiple autonomous agents (Caves, 2003). Industries such as feature film production (Mezias and Mezias, 2000), advertising (Grabher, 2001) and book publishing (Heebels and Boschma, 2011) are based on project-based production systems involving creative and business-oriented entrepreneurs. Success of these entrepreneurs is dependent on their embeddedness in interfirm networks, communities and scenes (Grabher, 2001). Interfirm collaborations in creative industries serve not only as conduits of information flows but also as hierarchies of reputation and status (Currid, 2007; Heebels and Boschma, 2011).

The video games industry is particularly interesting since it is a creative industry, where each new video game can be understood as a temporary project in itself (Tschang, 2007). Within each project, the functional activities are distributed over the firms involved. Each video game is unique, since it introduces new gameplays, new perspectives, new genre combinations, new characters or enhanced graphics (Baldwin and Clark, 2000; Salen and Zimmerman, 2003). The production of a video game is carried out as a project involving a development company and a publishing company, although some development companies publish their own games and some publishing companies set up in-house development studios.

In this particular form of coordination, the relationship between publishers and developers is crucial. Indeed, like in other creative industries, developers play the role of generating creative content, from the programming skills to the artistic designs, and publishers play the role of introducing such creative content onto the market, from financing to marketing issues. The production process of a video game is characterized by the coalescence of art and technology and involves character designers, graphic artists, programmers, managers and marketers (Caves, 2003). Proximity is then of crucial importance for effective communication and efficient learning. In addition, proximity contributes to solving conflicts that might arise from different incentives structures. Formally, we consider that two firms are connected when these organizations are involved in the production of the same video game.

We collected data on all firms that developed or published one or more video games for a video game console (Table 7.1). Such games are played using a video game console linked to a television or monitor, rather than PC games or other digital hardware. The constructed database contains information such as years of production of the game, number of games produced, location and game level data such as co-production partners, role played in the production, computer platform compatibility and genre. The database covers the years 2005, 2006 and 2007. The data is a compilation of various data sources. The starting point was the Game Documentation 


\section{Table 7.1 Collaboration patterns}

\begin{tabular}{lc}
\hline & $2005-07$ \\
\hline Number of firms & 757 \\
Number of games & 4857 \\
Games per firm (mean) & 6416 \\
No. of games involving: & \\
- A single firm & 455 \\
- Two firms & 4018 \\
- Three firms & 355 \\
- Four firms & 16 \\
- Five firms & 8 \\
- Six firms & 5 \\
\hline
\end{tabular}

and Review Project Mobygames. ${ }^{2}$ The Mobygames website is a comprehensive database of software titles and covers the date and country of release of each title, the platform on which the game can be played, and the name of the publisher and developer of the game. The project aims to include all games that have ever been developed and published in the video games industry. To obtain data on entry, exit and location of firms and to control and monitor the quality of the Mobygames data we also consulted the German Online Games Datenbank. ${ }^{3}$ This online database is complementary to the Mobygames database in that it provides more detailed information on the location of companies and backgrounds of entrepreneurs. In the rare case that neither of the two databases provided this information or in the rare case that the information in the two databases was contradictory, other online or hardcopy resources were consulted.

We excluded firms that developed only one game in the entire sample of games. We limited our analysis to the games produced by two firms and only two firms. Including games developed by more than two firms generates two problems. First, it is impossible to assess which partners are actually collaborating, so we have to assume that all partners are equally connected. Second, each game is thus a clique by itself, which could artificially increase the level of network closure and bias the estimation of transitivity. Because such games are marginal ${ }^{4}$ during the period considered, we opted for excluding them from the analyses.

The resulting network involves $n$ actors and can be represented as a $n \times n$ matrix $x=(x i j)$, where $x i j=1$ represents the joint production of a video game by firm $i$ and firm $j(i, j=1, \ldots, n)$. For the construction of the longitudinal relational database, it is assumed that ties are active during the year of release of a given video game. As such, if a game is released in 2005 by actor $i$ and actor $j$ (regardless of the month), then we assume that 
Table 7.2 Network dynamics: relational and composition change

\begin{tabular}{lccc}
\hline Observed period & Ties created & Ties dissolved & Ties maintained \\
\hline $2005-06$ & 508 & 526 & 300 \\
$2006-07$ & 594 & 504 & 304 \\
\hline
\end{tabular}

Table 7.3 Network structural descriptive statistics

\begin{tabular}{lcccc}
\hline Observed Year & Number of Firms & Number of Ties & Average degree & Density \\
\hline 2005 & 462 & 826 & 1.788 & 0.004 \\
2006 & 463 & 808 & 1.745 & 0.004 \\
2007 & 431 & 898 & 2.084 & 0.005 \\
\hline
\end{tabular}

a relation exists between $i$ and $j$ for the year 2005, and only for that year. It means that the tie will be dissolved in 2006 if $i$ and $j$ do not release a game together again. Moreover, relations are not directed because we assume that ties are always reciprocated. All relations are also dichotomized, ${ }^{5}$ which means that $x i j=1$ even if the number of games produced by $i$ and $j$ is $>1$ during a given year. For technical reasons, the network database corresponds to a set of yearly matrices with the same $n \times n$ size, with $n=$ 479.

The resulting network dynamics, summarizing the number of ties created, maintained or dissolved from one year to another is presented in Table 7.2, while Table 7.3 provides some descriptive statistics about the longitudinal network database, including the number of firms and the number of ties for each year included in the statistical analysis.

\section{Stochastic Actor-oriented Models (SAOM)}

A common issue related to the statistical analysis of network structures as the dependent variable is the conditional dependencies between observations. For instance, dyads that have actors in common cannot be treated as statistically independent observations. This violates standard statistical procedures like OLS and logistic regressions that assume independence among observations. In order to provide a correct statistical treatment of network structures, a class of dynamic models based on Markov random graph has been developed not only to account for such structural dependencies (Wasserman and Pattison, 1996) but also to model them (Snijders et al., 2010). In this chapter, we use Stochastic Actor-oriented Models (SAOM) implemented in the SIENA ${ }^{6}$ statistical software (Ripley 
et al., 2011). SAOM are dynamic models that allow researchers to include variables at an individual level, at a structural level but also at a dyadic level, which is required by our research question. Therefore, it has been acknowledged recently that SAOM open new areas of inquiries in economic geography (Ter Wal and Boschma, 2009; Maggioni and Uberti, 2011). So far, SAOM have been applied to analyse the dynamics of global and regional knowledge networks, for instance by Giuliani (2010) on a knowledge network of a wine cluster in Chile, by Balland (2012) on R\&D collaboration networks in Europe, and by Ter Wal on invention networks in Germany (2013). The main characteristics of SAOM are described below. For a general introduction to SAOM, see Snijders et al. (2010), for more technical details, see Snijders et al. (2001).

Different principles govern the way network evolution is modeled in SAOM. The first principle is related to the Markovian nature of the model, because change probability only depends on the current state of the network, and not on its past configurations. Said differently, the model does not have a memory of past network structures, which should therefore be included as exogenous variables (Steglich et al., 2010). The second principle is related to the idea of non-simultaneity in group formation. Time runs continuously between observations, and actors can change only one tie variable at a time. Three actors can only be connected as a result of sequence of ties between the three pairs of actors. Finally, the observed network dynamics is supposed to be the result of micro-decision of actors. Such relational choices are based on their preferences and constraints. Network structures change because actors develop strategies to create ties with other actors (Jackson and Rogers, 2007), based on their awareness of the network configuration. Indeed, it is assumed that organizations are actors, capable of elaborating their strategic decisions.

The relational choices of actors drive the evolution of network structures because at stochastically determined moments they can change their relations with other actors by deciding to create, maintain or dissolve ties. More formally, these opportunities are determined by a rate function in which opportunities to collaborate occur according to a Poisson process with rate $\lambda i$ for each actor $i$. Given that an actor $i$ has the opportunity to make a relational change, the choice for this actor is to change one of the tie variables $x i j$, which will lead to a new state $x, x \in C\left(x^{0}\right)$. At this stage, a traditional logistic regression is used to model choice probabilities (Snijders et al., 2010):

$P\left\{X(t)\right.$ changes to $x \mid i$ has a change opportunity at time $\left.t, X(t)=x^{0}\right\}$

$$
=p_{i}\left(x^{0}, x, v, w\right)=\frac{\exp \left(f_{i}\left(x^{0}, x, v, w\right)\right)}{\sum_{x^{1} \in C\left(x^{0}\right)} \exp \left(f_{i}\left(x^{0}, x^{1}, v, w\right)\right)}
$$


When actors have the opportunity to change their relations, they choose their partners by trying to maximize their objective function with random perturbations. In a first stage, actor $i$ can only attempt to maximize its objective function by trying to produce a video game with actor $j$, but this collaboration is only realized if actor $j$ accepts on the basis of its own objective function. ${ }^{7}$ Thus, changes in network ties are modelled according to a utility function at the node level which is the driving force of network dynamics. The objective function describes preferences and constraints of firms: to be linked with others that are geographically proximate might be one (Carayol and Roux, 2009). More formally, collaboration choices are determined by a linear combination of effects, depending on the current state $\left(x^{0}\right)$, the potential new state $(x)$, individual attributes ${ }^{8}(v)$ and proximity $(w)$ :

$$
f_{i}\left(x^{0}, x, v, w\right)=\sum_{k} \beta_{k} s_{k i}\left(x^{0}, x, v, w\right)
$$

As proposed by Snijders (2001), the estimation of the different parameters $\beta_{k}$ of the objective function is achieved by the mean of an iterative Markov chain Monte Carlo algorithm based on the method of moments. The stochastic approximation algorithm simulates the evolution of the network and estimates the parameters $\beta_{k}$ that minimise the deviation between observed and simulated networks. Over the iteration procedure, the provisional parameters of the probability model are progressively adjusted in a way that the simulated networks fit the observed networks. The parameter is then held constant to its final value, in order to evaluate the goodness of fit of the model and the standards errors.

\section{MEASURING PROXIMITY DIMENSIONS}

Measuring proximity represents an empirical challenge for each of its dimensions. Indeed, the most recent congress on Proximity, held in Poitiers in October $2009,{ }^{9}$ concluded that the operationalization of the proximity concepts is now one of the major issues to be taken up by the 'Proximity Dynamics' group. We follow the seminal analytical distinction in five dimensions of proximity proposed by Boschma (2005) (Table 7.4). For a similar attempt of operationalization of these five dimensions in a different research context, see Balland (2012).

\section{Cognitive Proximity}

Cognitive proximity refers to the similarity of knowledge bases of two organizations, i.e. the distribution of knowledge endowments across two 
Table 7.4 Operationalization of the proximity dimensions

\begin{tabular}{ll}
\hline Variable & Operationalization \\
\hline Cognitive proximity & Same genres of VG \\
Geographical proximity & Inverse of physical distance (natural log) \\
Social proximity & Same games produced previously (nb) \\
Organizational proximity & Same group of firms (dummy) \\
Institutional proximity & Same country (dummy) \\
\hline
\end{tabular}

agents. Such knowledge bases can be extracted from the final products, i.e. video games, each organization has produced. As such, we construct a relevant industry-specific measure of cognitive proximity. Contrary to most empirical studies, we adopt an asymmetric, directed measure of cognitive proximity. ${ }^{10} \mathrm{We}$ follow Balland, Boschma and Frenken (2011) who show that adopting a featural rather than a distance approach allows accounting for the fact that actor $i$ might be more cognitively proximate to $j$ than $j$ to $i$. To construct such a directed measure of proximity, we rely on information on the genres of the video games produced by companies in the 5 years prior to the focal year. Each video game is categorized into one or multiple genres. The genres that firms have covered represent the cognitive framework in which video games firms operate. In order to calculate the cognitive proximity between two firms, we measured the number of genres that firm $i$ and firm $j$ share divided by the total number of genres covered by firm $i$ and firm $j$, respectively. As a result the measure will be asymmetric. In particular, we assume that firms have a maximum attention span. If the attention span of two firms overlaps, firms are cognitively proximate.

\section{Geographical Proximity}

As explained before, geographical proximity is measured in a restricted manner, as the physical distance separating two organizations, because socio-economic dimensions of proximity are included in the other forms of proximity. More precisely, we consider the inverse of the natural logarithm of the physical distance ('as the crow flies') between two firms ${ }^{11}$ in kilometres in order to consider non-linearity of transports costs. We obtained a maximum of 10 and a minimum of 0 by computing the natural logarithm of the distance between firms. As such, we subtracted the $\log$ of distance to 10 , in order to have a proximity measure, ranging from 0 for the most distant firms to 10 for the closest ones: $\operatorname{ProxGeo}_{\mathrm{ij}}=10-\ln \left(\right.$ dist $\left._{\mathrm{ij}}\right)$. 


\section{Social Proximity}

Social proximity is probably one of the most complex proximity dimensions to operationalize, since it refers to socially embedded relations between agents at the micro-level. To some extent, it is the degree of overlap between personal networks of the individuals of two firms. Since such information is in practice rarely available, we adopted a measure of social proximity referring to the extent to which organizations share prior mutual relationships. Such relationships carry information about potential future partners, and thereby increase the probability of engaging in future collaborations. Social proximity can be measured on the basis of the number of previous collaborations (Ahuja et al., 2009). More precisely, we counted the number of games that two actors have produced together during the five previous years, making the hypothesis that such interactions create social relationships. In order to compute this measure, we also considered games that have been produced by more than two firms. Note that social proximity could also have been classified as a structural endogenous network formation mechanism, known as the repetition mechanism (Rivera et al., 2010).

\section{Organizational Proximity}

Organizational proximity is defined as the membership of organizations to larger groups. In the case of the video game industry, such corporate groups are composed of a set of organizations ranging from the parent companies, their subsidiaries to their different establishments. Formally, we calculated a $1-0$ dummy variable which is equal to 1 if the two organizations involved in the production of the video game belong to the same firm, and 0 otherwise. In our dataset, we identified all firm ownership structures, allowing us to distinguish between the main office (headquarters) of each firm and its subsidiaries. As a result, we were able to identify whether two organizations involved in the production of a video game shared the same owner(s) and did therefore belong to the same legal entity.

\section{Institutional Proximity}

We define institutional proximity as belonging to the same institutional context. This 'macro' proximity dimension refers to the idea that shared formal or informal institutions increase communication and coordination in the production of video games. In this industry, a particularly relevant institutional context operates at the national level through common intellectual property right regimes, common language and common 
Table 7.5 Descriptive statistics of the proximity dimensions

\begin{tabular}{lcccr}
\hline & Mean & SD & Min & Max \\
\hline Cognitive proximity & 3.423 & 2.930 & 0 & 10 \\
Geographical proximity & 2.012 & 2.115 & 0 & 10 \\
Social proximity & 0.052 & 1.229 & 0 & 251 \\
Organizational proximity & 0.001 & 0.037 & 0 & 1 \\
Institutional proximity & 0.225 & 0.417 & 0 & 1 \\
\hline
\end{tabular}

culture of gaming. Therefore, we operationalize institutional proximity according to a binary measure, taking 1 if the pair of actors belong to the same country, and 0 if not (see Table 7.5).

\section{Control Variables}

In order to control for structural effects, we include two different variables that measure the influence of the network itself, i.e. how the structure of the video game network influences its further evolution. The first variable to be distinguished is the density effect, which can be interpreted as the constant term in regression analysis. It is an important structural determinant, that indicates the general tendency to form linkages. As specified by Snijders et al. (2010), this variable should always be included in SAOM to control for the cost of relationships. Indeed, it indicates why all nodes are not able to be fully connected to all others (McPherson et al., 1991). Density is measured by the out degree of firms:

$$
D_{i}=\sum_{j} x_{i j}
$$

We also control for the effect of transitivity, which leads to triadic network closure. Sociologists have for instance observed that friends of friends become friends (Davis, 1970; Holland and Leinhardt, 1971), and the main idea is that trust can be provided not only by direct relationships but also by indirect relationships. Although transitivity can be measured in several ways, the most straightforward is based on the counts of number of transitive triplets of actors, i.e. the number of times an actor $i$ is tied with two actors that are partners themselves (Ripley et al., 2011):

$$
T_{i}=\sum_{j<h} x_{i j} x_{i h} x_{j h}
$$

Profile similarity is a variable that control for the fact that firms have a preference to stand for the role of publisher or developer in the process 
of game creation. First, we create a profile variable ranging from 0 to 10 in order to indicate the tendency of actors to publish. The tendency to publish is obtained by dividing for each actor $i$ the number of games in which $i$ has the role of publisher, divided by the total number of games in which $i$ was involved. We multiplied this ratio by ten. In order to control for the fact that a publisher prefers ties with developers and developers with publishers, we created a profile similarity variable: ${ }^{12}$

$$
P S_{i j}=1-\left(\mid v_{i}-v_{j}\right) / r_{\mathrm{v}}
$$

\section{EMPIRICAL RESULTS}

The relational dynamics of the video game industry from 2005 to 2007 is modelled in order to evaluate the influence of geographical, organizational, institutional, cognitive and social proximity on the formation of economic networks. Results of parameter estimations are presented in Table 7.6. The baseline model includes the different control variables. The intermediate model adds geographical, social and cognitive proximity. The final model includes all the proximity dimensions and the controls. All parameter estimations are based on 1000 simulation runs, and convergence

\section{Table 7.6 Estimation results: parameter estimates and standard deviations}

\begin{tabular}{|c|c|c|c|c|c|c|}
\hline & \multicolumn{2}{|c|}{ Baseline model } & \multicolumn{2}{|c|}{ Intermediate model } & \multicolumn{2}{|c|}{ Final model } \\
\hline & $\beta$ & $\mathrm{SD}$ & $\beta$ & $\mathrm{SD}$ & $\beta$ & $\mathrm{SD}$ \\
\hline \multicolumn{7}{|l|}{ Proximity dimensions } \\
\hline Cognitive proximity & & & $0.054 * * *$ & 0.013 & $0.052 * * *$ & 0.009 \\
\hline Geographical proximity & & & $0.048 * * *$ & 0.007 & $0.042 * * *$ & 0.01 \\
\hline Social proximity & & & $0.066^{* * *}$ & 0.008 & $0.05^{* * *}$ & 0.006 \\
\hline $\begin{array}{l}\text { Organizational } \\
\text { proximity }\end{array}$ & & & & & $1.164 * * *$ & 0.135 \\
\hline Institutional proximity & & & & & -0.016 & 0.056 \\
\hline \multicolumn{7}{|l|}{ Control variables } \\
\hline Profile similarity & $-1.127 * * *$ & 0.054 & $-1.086^{* * *}$ & 0.061 & $-1.113^{* * *}$ & 0.066 \\
\hline Density & $-2.112 * * *$ & 0.027 & $-2.208 * * *$ & 0.03 & $-2.219 * * *$ & 0.033 \\
\hline Transitive triads & $0.928 * * *$ & 0.056 & $0.782 * * *$ & 0.053 & $0.745^{* * *}$ & 0.051 \\
\hline
\end{tabular}

Notes:

$\mathrm{N}=479$

For standard deviations: ${ }^{*} \mathrm{p}<0.10 ;{ }^{* *} \mathrm{p}<0.05 ;{ }^{* * *} \mathrm{p}<0.01$. 
of the approximation algorithm is excellent for all the variables of the three different specifications ( $t$-values $<0.1$ ). The parameter estimates of SAOM can be interpreted as non-standardized coefficients obtained from logistic regression analysis (Steglich et al., 2010). Therefore, the $\beta$ reported in Table 7.6 are log-odds ratio, corresponding to how the log-odds of tie formation change with one unit change in the corresponding independent variable. A discussion of the results is presented below in order to consider specificities of the video games industry in our interpretation.

\section{Proximity Dimensions}

The upper part of Table 7.6 reports the influence of proximity mechanisms on partner selection. We evaluate whether firms prefer to collaborate with other firms that have similar attributes. The effect of cognitive proximity is positive and significant. This result confirms the idea that developers and publishers need similar knowledge bases in terms of video games genres in order to combine technological, design and marketing skills involved in the co-production of video games. Broekel and Boschma (2012) found that cognitive proximity matters for technological knowledge exchange in the Dutch aviation industry, but our model extends this result by showing that similarity of knowledge bases is also important to collaborate efficiently in creative industries. Investing the spatial dimension of networks, we also find a positive and significant impact of geographical proximity on network dynamics. Indeed, organizations prefer to produce video games when they are close in terms of physical distance. Even when controlling for the effects of the other proximity dimensions, we confirm the findings of empirical network studies that found evidence for the importance of geographical proximity (Autant-Bernard et al., 2007; Broekel and Boschma, 2012; Balland, 2012; Ter Wal, 2013). Thus geographical proximity is not only important for high-tech industries, but also for creative industries. This result does not support the 'death of distance thesis', as developers and publishers still need proximity to share tacit knowledge. An additional explanation is that video games are creative products that are technologically complex which require more inter-firm collaboration at shorter geographical distances (Sorenson et al., 2006).

Social proximity is also a strong predictor of the likelihood that two firms will co-produce a video game. Indeed, actors tend to repeat their relations over time, leading to a certain level of stability of network structures over time. Autant-Bernard et al. (2007) find a similar result for collaboration choices in high technologies at a European level. Interestingly, we also observe that organizational proximity is an important factor of 
collaboration. Publishers and developers prefer to collaborate when they belong to the same corporate group. It appears that trust is important to reduce uncertainty concerning the behavior of the partner, but it also reveals a strategy of (large) groups of video games firms. Although they promote the creation of separate units for publishing/developing games, they also tend to favour internal collaborations to avoid unintended knowledge spillovers. This result is in line with the findings of Balland (2012) in the context of the GNSS (Global Navigation Satellite Systems) industry in Europe. Institutional proximity, however, does not have a significant impact of tie formation. This means that, when controlling for physical distance, ${ }^{13}$ firms located in the same country are not more likely to produce a game together. This result might be related to the fact that national institutional regimes are converging with the globalization of the video games industry. In sum, we confirm the effect of proximity on the formation of creative networks, and the results of the model seem to be in line with other studies of high-tech networks.

\section{Control Variables}

The lower part of Table 7.6 reports the influence of control variables, i.e. structural and individual mechanisms. Structural network variables concern density and transitive triads. We found a negative and significant impact of the density effect. This variable indicates the costs of linkages which inhibit firms to be fully connected. For the transitivity variable, we found a positive and significant effect. This result indicates that firms are more likely to produce video games with partners of partners. Both results are in line with other empirical studies (Balland, 2012; Ter Wal, 2013). With respect to the individual characteristics, profile similarity is negative and significant, confirming our expectations that developers are more likely to collaborate with publishers, and vice versa.

\section{CONCLUSION}

In this chapter, we analysed the formation of economic networks based on joint collaborations of firms in the production of video games. We have employed a SAOM to analyse the probability that two actors collaborate on the basis of their proximity. Following the analytical distinction proposed by Boschma (2005) and the operationalization by Balland (2012), proximity does not only refer to the geographical dimension, but also to the organizational, institutional, cognitive and social forms. Geographical proximity is measured by the inverse of the 
physical distance, organizational proximity refers to belonging to the same corporate group, institutional proximity concerns belonging to the same national regime, social proximity is based on previous repeated collaborations and cognitive proximity is based on the overlap of genres of video games. Our empirical study suggests strong evidence for the role played by all proximity dimensions on economic network formation, except institutional proximity, which is not statistically significant.

This chapter contributes to the emerging literature that explicitly analyses the relationship between proximity and economic networks (Ponds et al., 2007; Hoekman et al., 2010; Boschma and Frenken, 2010; Cassi and Plunket, 2010; Brossard and Vicente, 2011; Vicente et al., 2011; Balland, 2012; Broekel and Boschma, 2012; Broekel and Hartog, 2013; Ter Wal, 2013). It should be noted, however, that this research question raises a set of issues that should be taken up in further studies. First, it has become more and more recognized that together with the structural level stressed by scholars from network theory, and individual characteristics stressed by authors from organization science, proximity is an important determinant of network formation.As such, we stress the importance of a more integrated framework composed by proximity, structural and individual mechanisms to analyse the formation of economic networks. Such an integrated framework is important to control for different forces operating at a different level (structural, individual, dyadic) but also to understand in which conditions endogeneity, heterogeneity or proximity is the most important driver force for the formation of economic networks.

Second, although the influence of different proximity dimensions has been evidenced, few studies investigate how this influence is changing over time. As stressed by Rivera et al. 2010 (p. 108): 'as networks evolve so too do the rules that govern their evolution'. For instance, the role of geographical proximity and spatial concentration might be intrinsically related to the life cycle of industries (Audretsch and Feldman, 1996; Neffke et al., 2011). The same applies for network structures that evolve with the industry (Bonaccorsi and Giuri, 2001; Orsenigo et al., 2001; Gay and Dousset, 2005). We claim there is a strong need for analysis of the changing role of proximity with the industrial evolution, because different needs of proximity can be related to different market configurations, innovation opportunities, technological change and discontinuities (Abernathy and Clark, 1985; Klepper, 1996, 1997). This is an important step to adopt a true evolutionary approach of network dynamics. Recently, Ter Wal (2013) analysed the changing role of geographical proximity on collaboration among German inventors over time. Balland, De Vaan and Boschma (2013) extended the analysis to the five forms of proximity at a global 
level, and detected that the forces behind network formation depend on the degree of maturity of an industry.

Third, our analysis focuses on a form of collaboration network, while several other channels of knowledge transfer exist. Although an increasing number of study analyses collaboration networks, it is crucial that researchers turn now on the analysis of the role of proximity on other mechanisms of knowledge transfer, like mergers and acquisitions (Ahuja and Katila, 2001, Siegel and Simons, 2010), informal communications (Dahl and Pedersen, 2004), collaborative projects (Grabher and Ibert, 2006), labour mobility (Almeida and Kogut, 1999), spin off (Klepper, 2002) or patent citations (Jaffe et al., 1993). Explaining such processes would be an important step toward the understanding of the role of proximity on knowledge transfer and interactive learning more generally.

\section{NOTES}

1. For a survey of the contributions made by scholars from the French school of proximity, the reader is referred to Carrincazeaux, Lung and Vicente (2008). For a discussion of the conceptual relationship between the main proximity approaches in the school, see Balland, Boschma and Frenken (2011).

2. The Game Documentation and Review Project Mobygames can freely be consulted at http://www.mobygames.com. The Mobygames database is a catalogue of 'all relevant information about electronic games (computer, console, and arcade) on a game-bygame basis' (http://www.mobygames.com/info/faq1\#a). The information contained in the MobyGames database is the result of contributions by the website's creators as well as voluntarily contribution by Mobygames community members. All information submitted to MobyGames is checked by the website's creators and errors can be corrected by visitors to the website.

3. 'Online Games Datenbank' can freely be consulted at http://www.ogdb.de.

4. See Table 7.1: 7.9\% of the total of games developed from 2005 to 2007 (384/4857).

5. The statistical model used in this chapter is only implemented for dichotomized networks.

6. This class of models is often referred to directly as SIENA models. SIENA stands for 'Simulation Investigation for Empirical Network Analysis'. The RSiena package is implemented in the R language and can be downloaded from the CRAN website: http:// cran.r-project.org/web/packages/RSiena/.

7. In other specifications, one actor can impose unilaterally the creation of a tie, but we use the so called 'unilateral initiative and reciprocal confirmation model', which has been often considered in the literature as the most realistic one for analysing collaboration decisions (see for instance Van de Bunt and Groenewegen, 2007; Balland, 2012; Ter Wal, 2013).

8. For the analysis, proximity variables are centred around the mean.

9. Dynamiques de proximité: le temps des débats, University of Poitiers, 14-16 October 2009.

10. Neffke and Svensson Henning (2008) use a similar argument to conceptualize asymmetric related variety.

11. Not computed for firms at distance 0 but directly replaced by 0 .

12. Where $\mathrm{v}$ is the tendency to publish and $\mathrm{Rv}$ is the difference between the highest and the lowest value of the tendency to publish variable. 
13. In other specifications where geographical proximity was not included in the model, institutional proximity has a positive and significant impact on tie formation.

\section{REFERENCES}

Abernathy, W. and Clark, K.B. (1985), Mapping the winds of creative destruction. Research Policy, 14, 3-22.

Agrawal, A., Cockburn, I. and McHale, J. (2006), Gone but not forgotten: knowledge flows, labor mobility, and enduring social relationships. Journal of Economic Geography, 6, 571-591.

Ahuja, G. and Katila, R. (2001), Technological acquisitions and the innovation performance of acquiring firms: a longitudinal study. Strategic Management Journal, 22, 197-220.

Ahuja, G., Polidoro, Jr., F. and Mitchell, W. (2009) Structural homophily or social asymmetry? The formation of alliances by poorly embedded firms. Strategic Management Journal, 30, 941-958.

Almeida, P. and Kogut, B. (1999), Localization of knowledge and the mobility of engineers in regional networks. Management Science, 7, 905-917.

Audretsch, D. and Feldman, M. (1996), Innovative clusters and the industry life cycle. Review of Industrial Organization, 11, 253-273.

Autant-Bernard, C., Billand, P., Frachisse, D. and Massard, N. (2007), Social distance versus spatial distance in R\&D cooperation: empirical evidence from European collaboration choices in micro and nanotechnologies. Papers in Regional Science, 86, 495-519.

Baldwin, C.Y. and Clark, K.B. (2000), Design Rules: The Power of Modularity. Cambridge, MA: MIT Press.

Balland, P.A. (2012), Proximity and the evolution of collaboration networks: evidence from research and development projects within the Global Navigation Satellite System (GNSS) Industry. Regional Studies, 46, 741-756.

Balland, P.A., Boschma, R. and Frenken, K. (2011), Dynamics of proximity and innovation networks: an evolutionary approach. Working Paper, Department of Economic Geography, Utrecht University.

Balland, P.A., de Vaan, M. and Boschma, R. (2013), The dynamics of interfirm networks along the industry life cycle: the case of the global video games industry, 1987-2007. Journal of Economic Geography, 13, 741-765.

Baum, J.A., Shipilov, A.V. and Rowley, T.J. (2003), Where do small worlds come from? Industrial and Corporate Change, 12, 697-725.

Bellet, M., Colletis, G. and Lung, Y. (1993), Économie des proximités. Revue d'Economie Régionale et Urbaine, 3, 357-606.

Bonaccorsi, A. and Giuri, P. (2001) Network structure and industrial dynamics: the long-term evolution of the aircraft-engine industry. Structural Change and Economic Dynamics, 12, 201-223.

Boschma, R. (2005), Proximity and innovation: a critical assessment. Regional Studies, 39, 61-74.

Boschma, R. and Frenken, K. (2010), The spatial evolution of innovation networks: a proximity perspective. In R. Boschma and R. Martin (eds), The Handbook on Evolutionary Economic Geography. Cheltenham, UK and Northampton, MA: Edward Elgar, pp. 120-135. 
Boschma, R.A. and Ter Wal, A. (2007), Knowledge networks and innovative performance in an industrial district: the case of a footwear district in the South of Italy. Industry and Innovation, 14, 177-199.

Bouba-Olga, O. and Grossetti, M. (2008), Socio-économie de proximité. Revue d'Economie Régionale et Urbaine, 3, 311-328.

Breschi, S. and Lissoni, F. (2009), Mobility of skilled workers and co-invention networks: an anatomy of localized knowledge flows. Journal of Economic Geography, 9, 439-468.

Broekel, T. and Boschma, R.A. (2012), Knowledge networks in the Dutch aviation industry: the proximity paradox. Journal of Economic Geography, 12, 409-433.

Broekel, T. and Hartog, M. (2013), Explaining the structure of inter-organizational networks using exponential random graph models. Industry and Innovation, 20, 277-295.

Brossard, O. and Vicente, J. (2011), Cognitive and relational distance in alliances networks: evidence on the knowledge value chain in the European ICT sector. In P. Cooke, C. De Laurentis, S. MacNeill and C. Collinge (eds), Platforms of Innovation: Dynamics of New Industrial Knowledge Flows, Cheltenham, UK and Northampton, MA: Edward Elgar.

Carayol, N. and Roux, P. (2009), Knowledge flows and the geography of networks: a strategic model of small world formation. Journal of Economic Behavior and Organization, 71, 414 427.

Carrincazeaux, C., Lung, Y. and Vicente, J. (2008), The scientific trajectory of the French school of proximity: interaction- and institution-based approaches to regional innovation systems. European Planning Studies, 16, 617-628.

Cassi, L. and Plunket, A. (2010), The determinants of co-inventor tie-formation. Proximity and network dynamics. Papers in Evolutionary Economic Geography, 10-15, Utrecht University, Utrecht.

Cassiman, B. and Veugelers, R. (2002), Spillovers and R\&D cooperation: some empirical evidence. American Economic Review, 92, 1169-1184.

Caves, R.E. (2003), Contracts between art and commerce. Journal of Economic Perspectives, 17, 73-83.

Cohen, W.M. and Levinthal, D.A. (1990), Absorptive capacity: a new perspective on learning and innovation. Administrative Science Quarterly, 35, 128-152.

Cowan, R., Jonard, N. and Zimmermann, J.B. (2007), Bilateral collaboration and the emergence of networks. Management Science, 53, 1051-1067.

Currid, E. (2007), The Warhol Economy: How Fashion, Art and Music Drive New York City. Princeton, NJ: Princeton University Press.

Dahl, M.S. and Pedersen, C. (2004), Knowledge flows through informal contacts in industrial clusters: myth or reality? Research Policy, 33, 1673-1686.

Davis, J.A. (1970), Clustering and hierarchy in interpersonal relations: testing two graph theoretical models on 742 sociomatrices. American Sociological Review, 35, 843-852.

Frenken, K. (2010), Geography of scientific knowledge: a proximity approach. Eindhoven Centre for Innovation Studies (ECIS) Working Paper 10.01, Eindhoven University of Technology, The Netherlands.

Gay, B. and Dousset, B. (2005), Innovation and network structural dynamics: study of the alliance network of a major sector of the biotechnology industry. Research Policy, 34, 1457-1475.

Gertler, M.S. (1995), 'Being there': proximity, organization, and culture in the 
development and adoption of advanced manufacturing technologies. Economic Geography, 71, 1-26.

Gilly, J.P. and Torre, A. (2000), Dynamiques de Proximité. Paris: L. Harmattan.

Giuliani, E. (2010), Network dynamics in regional clusters: the perspective of an emerging economy. Papers in Evolutionary Economic Geography, 10-14, Section of Economic Geography, Utrecht University.

Glückler, J. (2007), Economic geography and the evolution of networks. Journal of Economic Geography, 7, 619-634.

Grabher, G. (2001), Ecologies of creativity: the village, the group, and the heterarchic organisation of the British advertising industry. Environment and Planning $A, 33,351-374$.

Grabher, G. (2006), Trading routes, bypasses, and risky intersections: mapping the travels of 'networks' between economic sociology and economic geography. Progress in Human Geography, 30, 163-189.

Grabher, G. and Ibert, O. (2006), Bad company? The ambiguity of personal knowledge networks. Journal of Economic Geography, 6, 251-271.

Granovetter, M. (1985), Economic action and social structure: the problem of embeddedness. American Journal of Sociology, 91, 481-510.

Hall, P.A. and Soskice, D. (eds) (2001), Varieties of Capitalism. The Institutional Foundations of Comparative Advantage. Oxford: Oxford University Press.

Heebels, B. and Boschma, R. (2011), Performing in Dutch book publishing 1880 2008. The importance of entrepreneurial experience and the Amsterdam cluster. Journal of Economic Geography, 11, 1007-1029.

Hoekman, J., Frenken, K. and Tijssen, R. (2010), Research collaboration at a distance: changing spatial patterns of scientific collaboration within Europe. Research Policy, 39, 662-673.

Holland, P.W. and Leinhardt, S. (1971), Transitivity in structural models of small groups. Comparative Group Studies, 2, 107-124.

Jackson, M. and Rogers, B. (2007), Meeting strangers and friends of friends: how random are social networks? American Economic Review, 97, 890-915.

Jackson, M.O. (2008), Social and Economic Networks. Princeton, NJ: Princeton University Press.

Jaffe, A.B., Trajtenberg, M. and Henderson, R. (1993), Geographic localization of knowledge spillovers as evidenced by patent citations. Quarterly Journal of Economics, 108, 577-598.

Johns, J. (2005), Video games production networks: value capture, power relations and embeddedness. Journal of Economic Geography, 6, 151-180.

Kirat, T. and Lung, Y. (1999), Innovation and proximity - territories as loci of collective learning processes. European Urban and Regional Studies, 6, 27-38.

Klepper, S. (1996), Entry, exit, growth, and innovation over the product life cycle. American Economic Review, 86, 562-583.

Klepper, S. (1997), Industry life-cycles. Industrial and Corporate Change, 6, $145-182$.

Klepper, S. (2002), The capabilities of new firms and the evolution of the US automobile industry. Industrial and Corporate Change, 11, 645-666.

Maggioni, M. and Uberti, E. (2011), Networks and geography in the economics of knowledge flows. Quality and Quantity, 45(5).

McPherson, M., Smith-Lovin, L. and Cook, J.M. (2001), Birds of a feather: homophily in social networks. Annual Review of Sociology, 27, 415-444.

Mezias, J. and Mezias, S. (2000), Resource partitioning, the founding of spe- 
cialist firms, and innovation: the American feature film industry, 19121929. Organization Science, 11, 306-322.

Neffke, F. and Svensson Henning, M. (2008), Revealed relatedness: mapping industry space. Papers in Evolutionary Economic Geography, 08-19, Section of Economic Geography, Utrecht University.

Neffke, F., Svensson Henning, M., Boschma, R., Lundquist, K. and Olander, L. (2011), The dynamics of agglomeration externalities along the life cycle of industries. Regional Studies, 45, 49-65.

Nooteboom, B. (2000), Learning and Innovation in Organizations and Economies. Oxford: Oxford University Press.

Nooteboom, B., Van Haverbeke W., Duysters G., Gilsing V. and van den Oord, A. (2007), Optimal cognitive distance and absorptive capacity. Research Policy, 36, 1016-1034.

North, D.C. (1990), Institutions, Institutional Change and Economic Performance. Cambridge: Cambridge University Press.

Orsenigo, L., Pammolli, F. and Riccaboni, M. (2001), Technological change and network dynamics - lessons from the pharmaceutical industry. Research Policy, 30, 485-508.

Pecqueur, B. and Zimmerman, J.B. (2004), Les fondements d'une économie de proximités. In B. Pecqueur and J.B. Zimmerman (eds), Economie de proximités. Paris: Lavoisier.

Ponds, R., Van Oort, F. and Frenken, K. (2007), The geographical and institutional proximity of research collaboration. Papers in Regional Science, 86, 423-443.

Powell, W.W., White, D., Koput, K.W. and Owen-Smith, J. (2005), Network dynamics and field evolution: the growth of interorganizational collaboration in the life sciences. American Journal of Sociology, 110, 1132-1205.

Pratt, A. (2000), New media, the new economy and new spaces. Geoforum, 31, 425-436.

Rallet, A. and Torre, A. (1999), Is geographical proximity necessary in the innovation networks in the era of the global economy? GeoJournal, 49, 373-380.

Rallet, A. and Torre, A. (2001), Proximité Géographique ou Proximité Organisationnelle? Une analyse spatiale des coopérations technologiques dans les réseaux localisés d'innovation. Economie Appliquée, 4, 147-171.

Ripley, R., Snijders, T. and Preciado Lopez, P. (2011), Manual for RSiena. Oxford: University of Oxford, Department of Statistics; Nuffield College, May 1.

Rivera, M., Soderstrom, S. and Uzzi, B. (2010), Dynamics of dyads in social networks: assortative, relational, and proximity mechanisms. Annual Review of Sociology, 36, 91-115.

Robins, G. and Alexander, M. (2004), Small worlds among interlocking directors: network structure and distance in bipartite graphs. Computational and Mathematical Organization Theory, 10, 69-94.

Salen, K. and Zimmerman, E. (2003), Rules of Play: Game Design Fundamentals. Cambridge, MA: MIT Press.

Scott, A.J. (1997), The cultural economy of cities. International Journal of Urban and Regional Research, 21, 323-339.

Scott, A.J. (2004), Cultural-products industries and urban economic development. Urban Affairs Review, 39, 461-490.

Siegel, D. and Simons, K. (2010), Assessing the effects of mergers and acquisitions on firm performance, plant productivity, and workers: new evidence from matched employer-employee data. Strategic Management Journal, 31, 903-916. 
Snijders, T. (2001), The statistical evaluation of social network dynamics. In M. Sobel and M. Becker (eds), Sociological Methodology. Boston, MA; London: Basil Blackwell, pp. 361-395.

Snijders, T., Van De Bunt, G. and Steglich, C. (2010), Introduction to actor-based models for network dynamics. Social Networks, 32, 44-60.

Sorenson, O., Rivkin, J. and Fleming, L. (2006), Complexity, networks and knowledge flow. Research Policy, 35, 994-1017.

Steglich, C., Snijders, T. and Pearson, M. (2010), Dynamic networks and behavior: separating selection from influence. Sociological Methodology, 40, 329-393.

Suire, R. and Vicente, J. (2009), Why do some places succeed when others decline? A social interaction model of cluster viability. Journal of Economic Geography, 9, 381-404.

Ter Wal, A. (2013), The dynamics of the inventor network in German biotechnology: geographic proximity versus triadic closure. Journal of Economic Geography, forthcoming, doi: 10.1093/jeg/lbs063.

Ter Wal, A. and Boschma, R. (2009), Applying social network analysis in economic geography: theoretical and methodological issues. The Annals of Regional Science, 43, 739-756.

Ter Wal, A. and Boschma, R. (2011), Co-evolution of firms, industries and networks in space. Regional Studies, 45, 919-933.

Torre, A. (2008), On the role played by temporary geographical proximity in knowledge transmission. Regional Studies, 42, 869-889.

Torre, A. and Rallet, A. (2005), Proximity and localization, Regional Studies, 39, 47-59.

Tschang, F.T. (2007), Balancing the tensions between rationalization and creativity in the video games industry. Organization Science, 18, 989-1005.

Uzzi, B. (1996), The sources and consequences of embeddedness for the economic performance of organizations: the network effect. American Sociological Review, 61, 674-698.

Van De Bunt, G.G. and Groenewegen, P. (2007), An actor-oriented dynamic network approach: the case of interorganizational network evolution. Organizational Research Methods, 10, 463-482.

Vicente, J., Balland, P.A. and Brossard, O. (2011), Getting into networks and clusters: evidence from the Midi-Pyrenean Global Navigation Satellite Systems (GNSS) collaboration network. Regional Studies, 45, 1059-1078.

Wasserman, S. and Pattison, P. (1996), Logit models and logistic regressions for social networks: I. An introduction to Markov random graphs and $p^{*}$. Psychometrika, 61, 401-426.

Weterings, A. (2005), Do firms benefit from spatial proximity? Testing the relation between spatial proximity and the performance of small software firms in the Netherlands. Netherlands Geographical Studies, 336, KNAG, Utrecht. 